\title{
A Smart Management Approach Investigation for Hybrid Autonomous Power System
}

\author{
Nasri Sihem*, Ben Slama Sami**, Cherif Adnane* \\ * Department of Physics, Faculty of Sciences of Tunis, Farhat Hached University, Tunisia \\ ** Department of Information System, King Abdul-Aziz University, Jeddah, Saudi Arabia
}

\begin{tabular}{l} 
Article Info \\
\hline Article history: \\
Received May 26, 2015 \\
Revised Jul 24, 2015 \\
Accepted Aug 10, 2015 \\
\hline
\end{tabular}

Keyword:

Electrolyzer

Fuel Cell

Hydrogen

Management

Multi-agent

Solar

Ultracapacitor

\begin{abstract}
A novel design of system management based on multi-agents approach applied to an autonomous hybrid power system is proposed and investigated. The system under study integrates few elements, some serve to provide power requirements, while the others used to store energy. Among these items, we can mention a Solar Power Source namely (SPS) which works as primary source to feed a DC electric load. The system integrates also a secondary power source namely Power Recovery Source (PRS) based on a fuel cell technology used to compensate the power deficit if required. More than two kinds of energy storage, the first called Hydrogen Generation Element (HGE) including a water electrolyzer to store the energy in hydrogen form, while the second uses an Ultracapacitor Element (UE) to store the energy in its electrical form. To reach the well functioning of the system in order to satisfy the load requirements whatever the facts, an intelligent energy management approach based on multi-agent modeling is implemented and verified. Hence, the reliability and the effectiveness of the applied management strategy, which allows the coordination between the different energy sources and protects the system against any fluctuation, are proved by the obtained results from Matlab/Simulink.
\end{abstract}

Copyright (C) 2015 Institute of Advanced Engineering and Science. All rights reserved.

\section{Corresponding Author:}

Nasri Sihem,

Department of Physics,

Faculty of Sciences of Tunis,

Farhat Hached University, El Manar, PB 2092, Belvedere, Tunisia.

Email: nasri_sihem@live.fr

\section{INTRODUCTION}

Environmentally friendly, the renewable energy sources present reliable and promising solutions to replace the fossil fuels cause of the steady increase of its price along with concerns about emissions of greenhouse gases. Thus, the use of such renewable energy resources is becoming very large by integrating them into the equipments used for standalone or grid-tied systems. However, even its importance, these sources decline of its intermittent characteristic that requires the use of energy storage systems. For that, to perform the functioning of such system based on renewable energy resource, it is necessary to combine several kinds of sources and means of storage to obtain a hybrid system [1].

In this way, integrating solar power source with the use of hydrogen as energy storage system, leads to a non-polluting reliable energy source and reduces the total maintenance costs. In such system, the hydrogen can be generated via an electrolyzer supplied by the excess electrical energy issued from the renewable energy source. The $\mathrm{H}_{2}$ gas can then be stored for future use by a fuel cell (FC), which works as a secondary power source serving for the energy recovery if necessary [2]. The combination of Fuel cell with the ultra capacitor is an attractive choice due to their high efficiency, fast load-response, flexibility and modular structure for the use with other alternative sources such as PV systems or wind turbines [3]. Hence, the presence of ultracapacitor would be needed to ensure the energy storage and the energy recovery if 
necessary. For that, to ensure the control and management of such autonomous hybrid power system, an efficient and reliable operation technology is required. In this context, the application of multi-agent system approach appears reliable and proper to control hybrid systems this kind. This strategy of the system management has been expanded to include several application areas like transportation, power systems. Hence this technology is classified as the most intelligent and effective to model and to solve complex problems related to the control of systems [4].

Several researches and development works have been achieved on the hybrid power system as well as the strategies of management and a large number of publications are now available in the literature. In particular, considerable research works are interesting with the use of hydrogen as a storage medium for renewable energy systems were launched and added to the literature.

The authors in [5] present an approach to optimize a real time demand response model for a microgrid working in the island mode. Hence, they proposed multi-agent strategy at the residential and grid level for implementing its dynamic demand response. The work proposed by [6], presents an autonomous $\mathrm{PV} / \mathrm{FC}$ system in order to determine optimum design, control strategy, economic and performance of a $\mathrm{PV} / \mathrm{FC}$ hybrid power generation system without battery storage taking into account all losses in the system. This work treats a standard algorithm to manage the system. In fact, the overall efficiency achieved by the proposed work reaches at maximum 30\%. The authors in [7] develop a multi-agent system to control of a PV based microgrid including solar photovoltaic (PV) system coupled with battery storage. They treat and demonstrate the agents' abilities to island the PV-based microgrid in the event of an external fault, secure critical loads, and resynchronize the microgrid to the main grid after the fault is cleared. The work given by [8] focus on a decentralized management system of a hybrid agent paradigm-based electrical system. The proposed system is based on two renewable sources which are photovoltaic panel and wind turbine generator with a battery for energy storage. Hence, it adopted a management strategy that aims at quantifying and controlling production sources to adapt the energy consumed by consumption sources to that supplied by the system renewable production sources while reducing the operating cost of the system. A multi-agent system, where each production and consumption source is modeled by an agent, is proposed to represent the electrical system. The authors in [9] propose and develop a multi-agent system for distribution grid congestion management with electric vehicles. They present a two level hierarchical control method for integrating EVs into the distribution network to coordinate the self-interests and operational constraints of two actors, the EV owner and Distribution system operator (DSO). Then, they built a multi-agent system (MAS) that is based on the co-simulation environment of JACK, Matlab and Simulink.

This paper focus on analysis and development of a hybrid power system integrating a new strategy of system management based on multi-agents modeling that responds to several constraints encountered by the works cited previously as:

1) Replacing the use of batteries by storage means more efficient and environmentally harmless like hydrogen.

2) Using ultracapacitor device which, thanks to its fast dynamic response, allows managing the problem of storage on one hand and on the other settling that related to the load transitions.

3) Applying the strategy of system management to an autonomous hybrid power system that is dedicated to remote area application.

4) The adopted control strategy which is based on multi-agent can achieve the following performance:

a) Fast system response thanks to coordination between agents.

b) A better efficiency up to $40 \%$ which is not reached by the conventional control strategies.

The paper has been organized in the following way. The overall hybrid Power system (HPS) and its behavior are described and detailed in Section 2. Section 3 presents the multi-agent energy management approach accompanied by the description of the control algorithm. The simulation results have been discussed in Section 4, and finally, Section 5 establishes the conclusions.

\section{DESCRIPTION OF THE WHOLE HPS}

The proposed hybrid power system (HPS) consists of a few elements that each one is represented by an agent (see Figure 1). These elements are identified by:

1) Solar Power Source(SPS): based on a solar panel with maximum power point trackers (MPPT) and used as a primary energy source.

2) Hydrogen Generation Element (HGE): characterized by the use electrolyzer for $\mathrm{H}_{2}$ production.

3) Pressurized tank for $\mathrm{H}_{2}$ gas storage.

4) Power Recovery Source (PRS) that includes a fuel cell with a DC-DC converter for $\mathrm{H}_{2}$ utilization. 
5) Ultracapacitor element (UE): for a short-time electricity energy buffer.

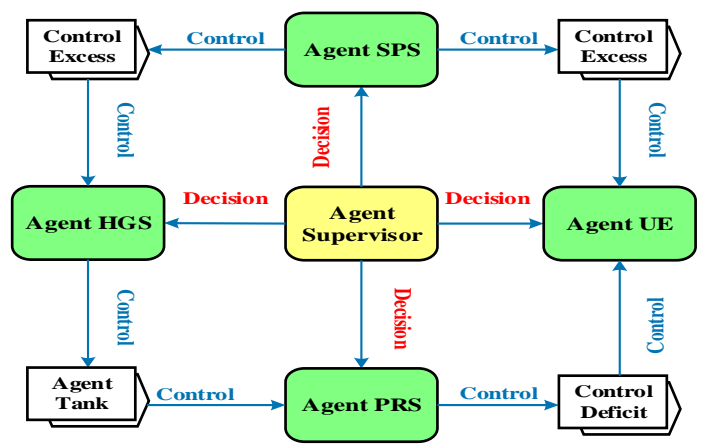

Figure 1. Scheme of the whole HPS

All the representative agents are monitored by the agent supervisor that controls and manages the system by the coordination and the communication between the different agents. Thus, the agent SPS controls the power coming from the solar in order to supply a DC load and sends the excess power to the storage elements. The storage agents either the HGE or UE are ready to store the excess power when they receive the decision order from the agent supervisor after the requirements analysis. At the same time, both HGE and UE agents control the inlet power coming from the SPS and send the checking results to the agent supervisor. The backup system is intervening in the deficit power case. At this moment, either the agent PRS or the agent UE receives the activation order from the agent supervisor to satisfy the load demand.

\subsection{The Agent SPS}

The agent SPS is dedicated to control the energy generated by the solar source. Indeed, The SPS is composed mainly by a solar cell which is the basic unit of photovoltaic modules that convert the sun's rays directly into electrical energy. Hence, the SPS is made up of a series and parallels range of solar cells connected together to provide the desired output terminal voltage and current. Indeed, the current of a solar cell is defined as a function of voltage [10]:

$$
I_{S P S}=I_{P H}{ }^{-I_{S}}\left[e^{\frac{V_{S P S}+R_{S} I_{S P S}}{V_{t}}}-1\right]-\frac{\left(V_{S P S}+R_{S} I_{S P S}\right)}{R_{P}}
$$

The agent SPS contains a DC/DC boost converter with MPPT which enables the SPS to work at the maximum power point in a highly fluctuated environment. Indeed, the SE agent normally uses a maximum power point tracking (MPPT) technique to continuously deliver the highest power through the converter to the load when there are variations in irradiation and temperature [11].

Table 1. Characteristics of SOLAREX MSX-60

\begin{tabular}{cc}
\hline Parameters & Values \\
\hline Maximal Power : $\mathrm{P}_{\max }$ & $60 \mathrm{~W}$ \\
Maximal Voltage: $\mathrm{V}_{\max }$ & $17.1 \mathrm{~V}$ \\
Maximal Current: $\mathrm{I}_{\max }$ & $3.5 \mathrm{~A}$ \\
Short-circuit Current: $\mathrm{I}_{\mathrm{SC}}$ & $3.8 \mathrm{~A}$ \\
Open-circuit Voltage: $\mathrm{V}_{\mathrm{OC}}$ & $21.1 \mathrm{~V}$ \\
Cell Numbers & $\mathrm{N}_{\mathrm{S}}=3 ; \mathrm{N}_{\mathrm{p}}=6$ \\
\hline
\end{tabular}

\subsection{The Agent HPS}

The agent PRS is characterized by the use of a proton exchange membrane fuel cell (PEMFC). In fact, the PRS works as a backup system that is dedicated to control the energy recovery by converting hydrogen into electricity. Thus, the calculation of the hydrogen consumption variations due to load changes is realized by Equation (3) and the total hydrogen consumption is calculated by the summation of the instant hydrogen consumption values [12]. 


$$
Q_{H_{2}}^{C}=\frac{{ }_{C E L L}}{2 \cdot F \cdot \eta^{P R S}} \cdot I_{P R S}
$$

Table 2. Characteristics of PEMFC (PRS)

\begin{tabular}{cc}
\hline Parameters & Values \\
\hline Maximal Power Load : $\mathrm{P}_{\max }$ & $40 \mathrm{~W}$ \\
Boost efficiency & $90 \%$ \\
Number of cells & 30 \\
Active Area per cell & $10 \mathrm{~cm}^{2}$ \\
Range of operating current & $0-20 \mathrm{~A}$ \\
Operating temperature & $20^{\circ}-80^{\circ}$ \\
\hline
\end{tabular}

\subsection{The Agent HGE}

The agent HGE is a kind of energy storage unit that is dedicated to control and ensure the energy storage in the chemical form (Checking hydrogen production). It is characterized by the use of a proton membrane exchange water electrolysis whose main function is to generate hydrogen gas by decomposing the water molecules into hydrogen and oxygen. The HGE use the electric current coming from the SPS to produce the hydrogen that will be then controlled by the agent tank in order to be stored. Using the law of Faraday, the rate of hydrogen generated by an electrolyzer is derived from the electrical current and it can be defined as follows [13]:

$$
Q_{H_{2}}^{P}=\frac{\eta^{H G E}{ }^{H}{ }_{C}}{2 . F} . I_{H G E}
$$

Table 3. Characteristics of Electrolyzer (HGE)

\begin{tabular}{cc}
\hline Parameters & Values \\
\hline Maximal Power Load : $\mathrm{P}_{\max }$ & $30 \mathrm{~W}$ \\
Number of cells & 15 \\
Active Area per cell & $5 \mathrm{~cm}^{2}$ \\
Range of operating current & $0-20 \mathrm{~A}$ \\
Operating temperature & $60^{\circ}-120^{\circ}$ \\
\hline
\end{tabular}

\subsection{The Agent Tank}

The main objective of this agent is to control the inlet and the outlet amount of hydrogen stored in a high pressure tank storage. In fact, the amount of $\mathrm{H}_{2}$ gas needed to be exploited by the PRS is directly issued from the HGE component based on the proportionality between the output power and the required amount of hydrogen used by the PRS component. The remaining hydrogen amount (the difference between the generated and the used amount of $\mathrm{H}_{2}$ gas) is transmitted to the tank storage. In this study, the dynamic of the tank storage is obtained as follows [14]:

$$
P_{T}-P_{T i}=Z \frac{Q_{H_{2}}^{I N} R T_{T}}{M_{H_{2}}{ }^{V} T}
$$

\subsection{The Agent UE}

The UE agent is a kind of energy storage unit that is dedicated to control the behavior of the ultracapcitor. Obviously, the UE has two statuses (charging and discharging corresponding to the renewable energy source and the load, respectively). In fact, when the power, sent from the SPS and the PRS, is insufficient to supply the load, the UE is discharged to meet the load demand as an energy supplier. In the opposite case, when the supply from the SPS exceeds the load demand and the HGE becomes unable to produce more $\mathrm{H}_{2}$ gas, the UE is charged and viewed as the load. Usually, there are two factors related to the performance of the system, state of charge (SOC) and the float charge current. Hence, the SOC is the index which would prevent the UE from overcharging and undercharging. It can be expressed as follows [15]: 


$$
\operatorname{SOC}_{U E}=\frac{V_{U E}^{2}}{V_{U E_{\max }^{2}}^{2}}
$$

The $\mathrm{V}_{\mathrm{UE}}$ and $\mathrm{V}_{\mathrm{UEmax}}$ are defined as the UE voltage and the USC maximum voltage respectively. Hence, the UE voltage can be calculated from Equation (7) [16].

$$
V_{U E}=R_{U E} \cdot I_{U E} \cdot \frac{1}{C} \int_{0}^{t}\left(I_{U E}-I_{U E}^{D H}\right) \cdot d t+V_{U E}(0)
$$

Table 4. Characteristics of Ultracapacitor (UE)

\begin{tabular}{ll}
\hline \multicolumn{1}{c}{ Parameters } & \multicolumn{1}{c}{ Values } \\
\hline Maximum State of charge: $\mathrm{SOC}_{\max }$ & 0.87 \\
Minimum State of charge : $\mathrm{SOC}_{\min }$ & 0.05 \\
Resistance: $\mathrm{R}_{\mathrm{UE}}$ & $25 \mathrm{~m} \Omega$ \\
Capacitance: $\mathrm{C}$ & $50 \mathrm{~F}$ \\
\hline
\end{tabular}

\subsection{The Agent Load}

The load agent is to manage thes load to make it a controllable energy resource. In autonomous system, the load also participates in the competition to inform on the current load power fluctuation.

\section{AGENT BASED SYSTEM FOR ENERGY MANAGEMENT}

Our work is specialized by a new energy management approach which is based on a multi-agent technique. This approach can be classified as an intelligent method used to manage the recovery and the storage of the energy. Indeed, multi-agent system is a system comprising intelligent agents that work together to achieve a global goal. This is a most exciting and fastest growing research field. Multi-agent system has a great potential for modeling of autonomous decision making entities, which can be used to model and operate an off-grid system. Hence, the multi-agent modeling can be done by representing each important element in the system as an intelligent agent. Intelligent agent provides platform to implement computational intelligent tools and mathematical tools for decision making of the different entities [17]. In addition, In order to model the multi-agent approach structure, we used the language Agent-UML (AUML) which is inspired of Unified Modeling Language (UML) that is specified by the use of agents. In fact, this language, graphical modeling, is dedicated to model and design systems based on agents interactions. In this case, the Agent-UML bids different kinds of modeling to represent the system and the interactions between its elements. Among them, we can cite the state-chart UML diagram that is classified as the most proper for describing agent's behavior. Thereby, this kind of diagram helps to understand the principle of interactions between agents and the activity of each of them (Figure 2). Hence, the agents change their state from one to another relying either on the happened events or on the received messages. Hence, each agent changes its state on the basis of the interactions that are occurred between the different agents according to the system requirements.

Figure 3, presents the UML sequence diagram that is used to describe and to represent the different interactions between the system agents during the energy storage and recovery events. This operation is done by comparing the load power value with the SPS power one. In addition, the supervisor agent sends functioning nature to the HGE agent and at the same time two other messages to the UE and PRS agents. The message sent to the HGE agent is a request to store the energy. The message sent to the PRS agent is a request to supply the energy by specifying the demanded power in the deficit power case. While the message sent to the UE agent may be a request to supply energy in the case of a power recovery or to store the energy in the excess power case [18]. 


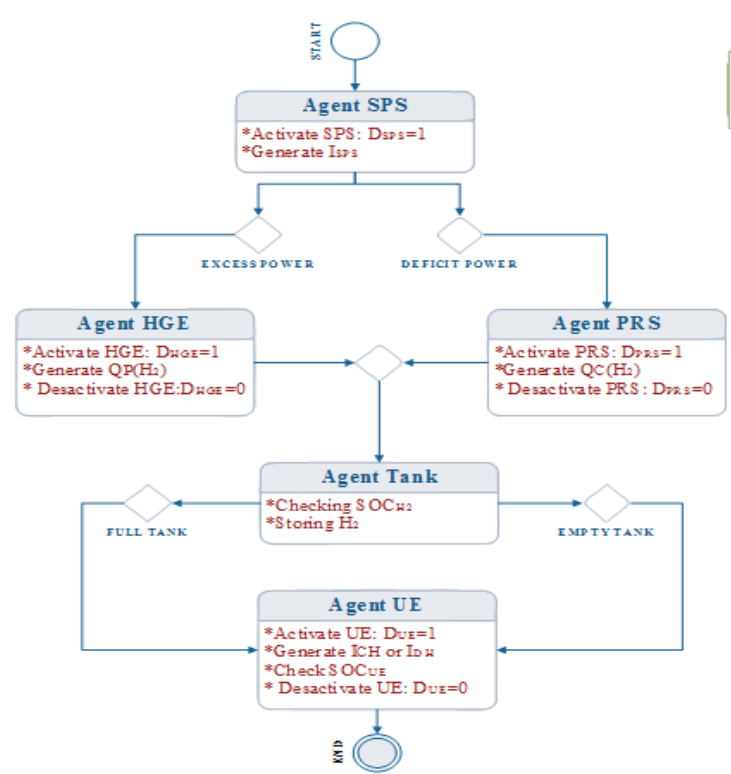

Figure 2. State Chart Diagram of the HES behavior

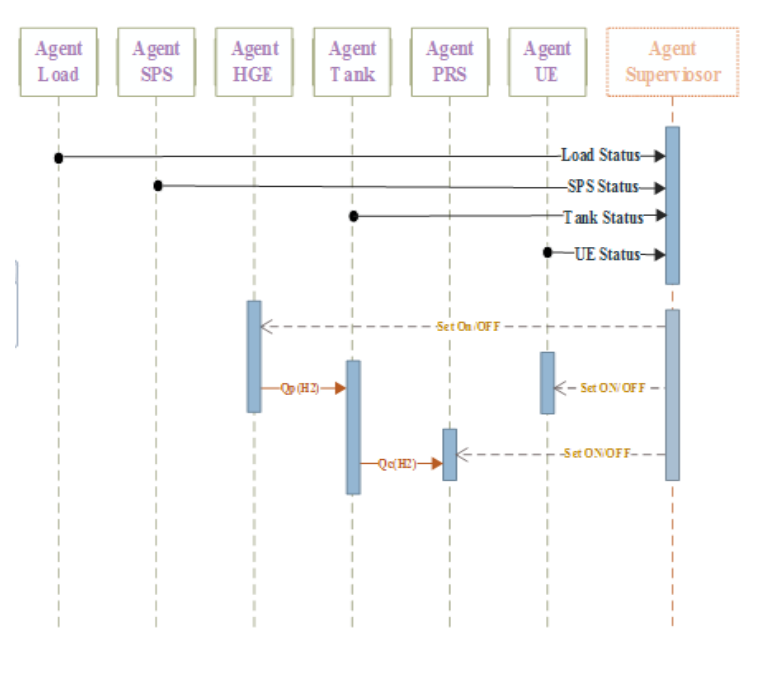

Figure 3. State Chart Diagram of the HES behavior

To summarize the agent based system behavior, which interests in the system response way to cope with changes; particularly the decisions taken to ensure the rapidity and the smooth system functioning through the coordination between the other agents, the different system states and transitions are described as follows:

State 1: Excess of power

Transition 1: $\mathrm{SOC}_{\mathrm{H} 2}<\mathrm{SOC}_{\mathrm{M}}$

Event 1: Hydrogen production $\rightarrow \mathrm{HGE}$ is on $\left(\mathrm{D}_{\mathrm{HGE}}=1\right)$

Transition 2: $\mathrm{SOC}_{\mathrm{H} 2}>\mathrm{SOC}_{\mathrm{M}}$ and $\mathrm{SOC}_{\mathrm{UE}}<\mathrm{SOC}_{\max }$

Event 2: $U E$ is charging $\rightarrow$ HGE is off $\left(D_{\mathrm{HGE}}=0\right)$ and $U E$ is on $\left(D_{U E}=1\right)$

Transition 3: $\mathrm{SOC}_{\mathrm{H} 2}>\mathrm{SOC}_{\mathrm{M}}$ and $\mathrm{SOC}_{\mathrm{UE}}>\mathrm{SOC}_{\max }$ $\left(\mathrm{D}_{\mathrm{UE}}=0\right)$.

Event 3: Stopping Storage process $\rightarrow$ HGE is off $\left(\mathrm{D}_{\mathrm{HGE}}=0\right)$ and $\mathrm{UE}$ is off

State 2: Deficit of power

Transition 4: $\mathrm{SOC}_{\mathrm{H} 2}>\mathrm{SOC}_{\mathrm{Mn}}$

Event 4: Hydrogen Consumption $\rightarrow$ PRS is on $\left(\mathrm{D}_{\mathrm{PRS}}=1\right)$

Transition 5: $\mathrm{SOC}_{\mathrm{H} 2}<\mathrm{SOC}_{\mathrm{Mn}}$ and $\mathrm{SOC}_{\mathrm{UE}}>\mathrm{SOC}_{\min }$

Event 5: $U E$ is discharging $\rightarrow$ PRS is off $\left(D_{P R S}=0\right)$ and $U E$ is on $\left(D_{U E}=1\right)$

Transition 6: $\mathrm{SOC}_{\mathrm{H} 2}<\mathrm{SOC}_{\mathrm{Mn}}$ and $\mathrm{SOC}_{\mathrm{UE}}<\mathrm{SOC}_{\text {min }}$ off $\left(\mathrm{D}_{\mathrm{UE}}=0\right)$.

Event 6: Stopping Recovery process $\rightarrow$ PRS is off $\left(\mathrm{D}_{\mathrm{PRS}}=0\right)$ and UE is

We should be noted that we have optimize the system sizing with the aim of not encounter a problem either in storage or recovery levels. This can be also one of the improvements that have occurred on the system.

\section{RESULTS AND ANALYSIS}

By applying the strategy of multi-agent, the system becomes able to manage every problem due to the lack of electricity or that related to energy storage. In fact, the multi-agent algorithm allows the system to improve performance and achieve a better yield. To demonstrate the reliability and the effectiveness and to shows the innovative modeling aspect of the studied system, we have used Matlab-Simulink environment which offers the possibility to design the agent's behavior through Stateflow modeling. This latter is used to model complex system and it seems suitable to implement our system. Hence, the system is simulated using experimental data profiles of solar radiation, solar temperature and user demands consumption that have been measured and collected in three consecutive days of the month of January. All this data are extracted from Tunisian meteorological database which leads us to achieve the following results. 
According to the obtained results, we can clearly observe that the agent SPS plays the role of a primary source for feeding a continuous load. Additionally, the load profile used is similar to an audiovisual load installed in a house. Thus, the agent SPS controls his entire power to be compared with the load demands (see Figure 4). We can remark that, cause of the weather conditions variations, sometimes the agent SPS cannot only satisfy the load demand. While, in the other case, we can see the SPS delivering an excess of power which must be managed then stored.

From Figure 5, we can deduce the decision made by the agent based system relying to status shown in Figure 4. Hence, the behavior of the agent responsible for system management is analyzed in the next subsections.

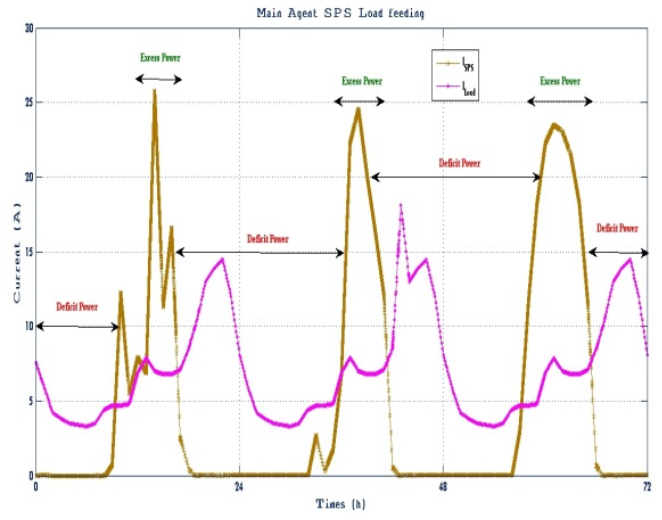

Figure 4. Agent SPS current control

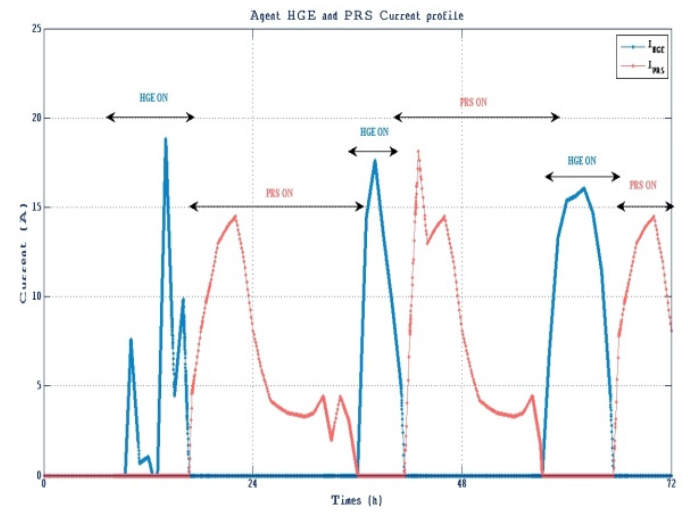

Figure 5. Agent HGE and PRS current profile

\subsection{Management of the Deficit Power}

This subsection deals with the treatment of the insufficiency of the energy supplied by the main source for the system. Hence, the applied management approach allows, intelligently and rapidly, ensuring the remained missing energy without affecting the operation of the load.

For more explanation, we treat the time interval between $0 \mathrm{~h}$ and $10 \mathrm{~h}$. In this time, the system declines of a deficit of power that requires a rapid intervention of the recovery energy sources. In this case, the agent supervisor has to check the energy flow rates presenting in the tank and the UE respectively. According to Figure 6, which presents the status of the tank storage, we can remark that in the same interval time, the tank is empty which means the impossibility of $\mathrm{H}_{2}$ gas delivering and causes the deactivation of the PRS. To maintain the load demands, the agent supervisor sends request to the agent UE in order to activate it (see Figure 7). Hence, this latter is used in its discharging mode which causes the decrease of energy gathered in the UE as well as the state of charge is reducing from its initial value which is $80 \%$.

In other times, we can see the intervening of the agent PRS to rectify the deficit thanks to the sufficient hydrogen stored amount.

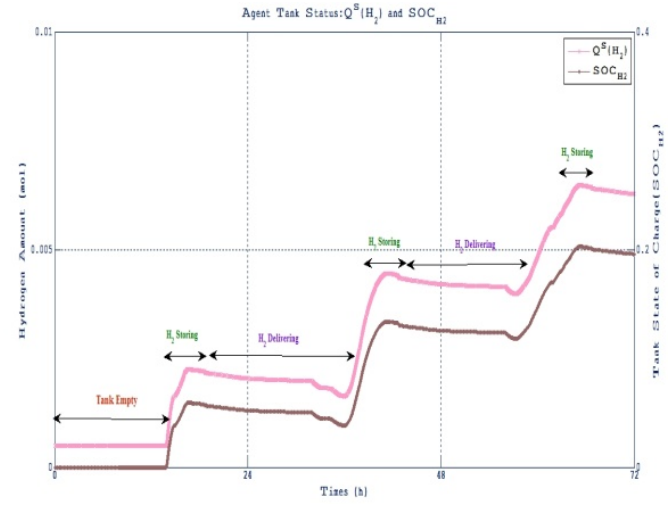

Figure 6. Agent Tank status checker

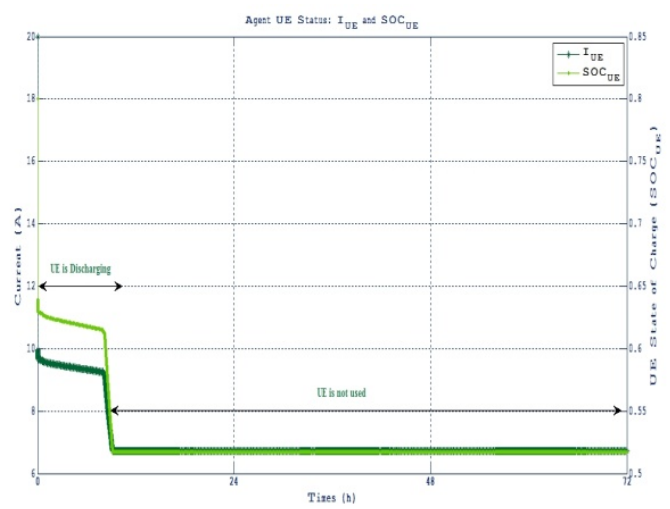

Figure 7. Agent UE Status checker

\subsection{Management of the Excess Power} the SPS agent.

In this subsection, we treat the behavior of the system along with the excess of energy provided by 
In the interval time between $10 \mathrm{~h}$ and $15 \mathrm{~h}$, the system provides an excess of power that has to be stored. For that, the tank status checking step must be achieved. Hence, according to the Figure 6, the tank is able to store hydrogen in this time. Consequently, the agent based system turn on the agent HGE which can explain the increase of the hydrogen stored quantity as well as the tank state of charge $\left(\mathrm{SOC}_{\mathrm{H} 2}\right)$. In addition, we can see that the system does not require the use of the agent UE to manage the problem of energy storage in this stage (see Figure 7). For that, the agent UE still inoperable in the case of appropriate tank status.

Finally, the Figure 8 is dedicated to show the decision made by the agent supervisor which is assigned to the activation and deactivation of each system component. It has been assumed that the agent SPS remained active during the entire simulation phase while the behavior of other agents varies depending on the system requirements variation. Additionally, in the same figure, we can see the performance provided by the system which seems to be best compared to that using energy management algorithm other than multi-agent strategy. Hence, according to the given result, the system adopted by our work reaches at maximum $47 \%$ as efficiency while in the same case of study with the classical method of management using simple algorithm the system efficiency does never exceed $20 \%$.
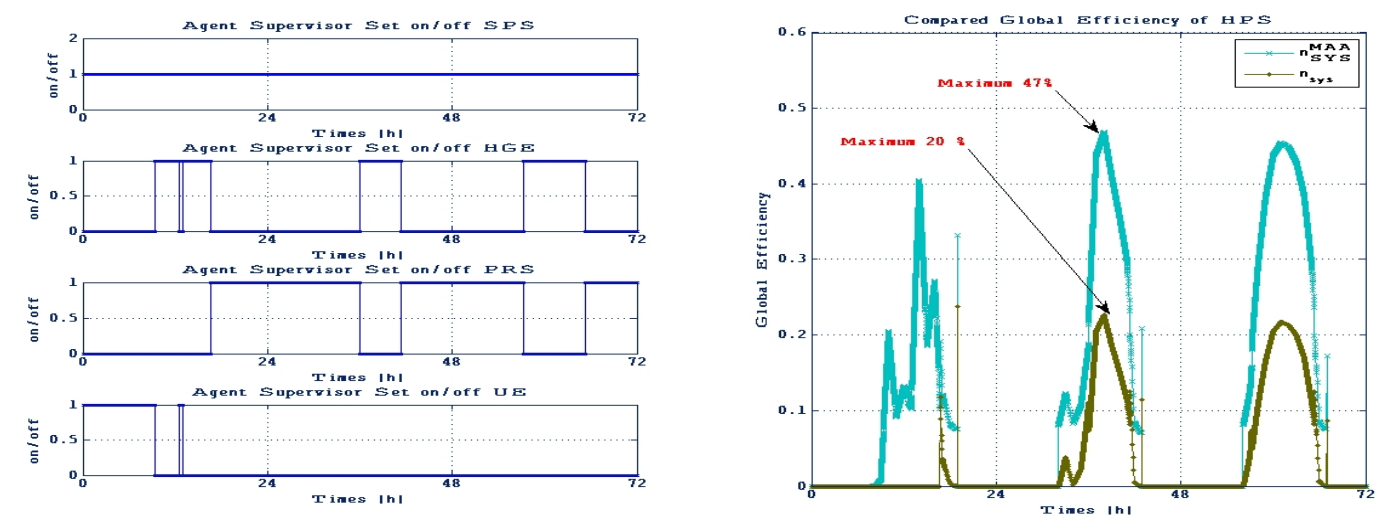

Figure 8. HPS System Status

We can deduce that the system ensures the coordination between each agent according to the decision values. Hence, the system reacts rapidly against any fluctuation or transition by virtue of the agents' communications that is clearly demonstrated and justified by the obtained simulation results. For this, we have proved that our applied management approach succeeded to respond smartly to the energy requirements in such autonomous hybrid power system.

\section{CONCLUSION}

In this paper, we proposed an intelligent approach of energy management based on multi-agent system dedicated to control the behavior of an off-grid hybrid power system. The aim of this control strategy is to analyze the problems of electricity production integration from fluctuating renewable energy sources, into the electricity supply. The multi-agent approach can be accommodated with the interaction among different kinds of agents. The applied strategy respects the specificity of the agent module. Hence, the use of these agents, keeps the optimal behavior of the load. The model of the studied system was established using MATLAB/Simulink. The obtained simulation results proved the reliability and feasibility of such hybrid electric system based on solar-hydrogen energy production destined to stand-alone application that can be applied for a remote area.

\section{REFERENCES}

[1] J. Lagorse, D. Paire, and A. Miraoui, "A multi-agent system for energy management of distributed power sources," Renewable Energy, Vol. 35, pp. 174-182, 2010.

[2] M. Castaneda, A. Cano, F. Jurado, H. Sanchez, and L. M. Fernandez, "Sizing optimization, dynamic modeling and energy management strategies of a stand-alone PV/hydrogen/battery based hybrid system," International Journal of Hydrogen Energy, Vol. 38, pp. 3830-3845, 2013.

[3] M. Uzunoglu, O.C. Onar, and M.S. Alam, "Modeling, control and simulation of a PV/FC/UC based hybrid power generation system for stand-alone applications," Renewable Energy, Vol. 34, pp. 509-520, 2009.

[4] M. Wooldridge, "MultiAgent Systems", Wiley, 2002. 
[5] R. Fazal, J. Solanki, and S. K. Solanki, "Demand Response using Multi-agent System,” IEEE, 2012.

[6] A. A. Elbaset, "Design, Modeling and Control Strategy of PV/FC Hybrid Power System," J. Electrical Systems, Vol. 7, No. 2, pp. 270-286, 2011.

[7] M. Pipattanasomporn, H. Feroze, and S. Rahman, "Securing critical loads in a PV-based microgrid with a multiagent system," Renewable Energy, pp. 1-9, 2011.

[8] A. K. Bodian, M. L. Daya, M. Ndiayeb, and P. A. Ndiaye, "Operation Optimal Dynamics of a Hybrid Electrical System: Multi Agent Approach,” Procedia Computer Science, Vol. 36, pp. 454-46, 2014.

[9] J. Hua, A. Saleem, S. You, L. Nordström, M. Lind, and J. Stergaard, "A multi-agent system for distribution grid congestion management with electric vehicles," Engineering Applications of Artificial Intelligence, Vol. 38, pp. 45$58,2015$.

[10] C. Li, X. Zhu, G. Cao, S. Sui, and M. Hu, "Dynamic modeling and sizing optimization of stand-alone photovoltaic power systems using hybrid energy storage technology," Renewable Energy, Vol. 34, pp. 815-826, 2009.

[11] A. A. Elbaset, "Design, Modeling and Control Strategy of PV/FC Hybrid Power System", J. Electrical Systems. Vol. 7, No. 2, pp. 270-286, 2011.

[12] P. M. Sudhakar, and B. M. Mohan, "Predictive and Optimizing Energy Management Of Photovoltaic Fuel Cell Hybrid Systems With Short Time Energy Storage," International Journal of Engineering Research and Applications (IJERA), Vol. 2, No. 6, pp. 550-556, 2012.

[13] O. C. Onar, M. Uzunoglu, and M.S. Alam, "Modeling, control and simulation of an autonomous wind turbine/photovoltaic/fuel cell/ultra-capacitor hybrid power system," Journal of Power Sources, Vol. 185, pp. 1273$1283,2008$.

[14] T. Lajnef, S. Abid, and A. Ammous, "Modeling, Control, and Simulation of a Solar Hydrogen/Fuel Cell Hybrid Energy System for Grid-Connected Applications," Hindawi Publishing Corporation Advances in Power Electronics, 2013.

[15] M. Hadartz, and M. Julander, "Battery-Supercapacitor Energy Storage," Master of Science Thesis in Electrical Engineering, Department of Energy and Environment, Division of Electric Power Engineering Chalmers University Of Technology, Göteborg, Sweden, 2008.

[16] L. Wei, Z. Xin-jian, C. Guang-yi, "Modeling and control of a small solar fuel cell hybrid energy system," Journal of Zhejiang University Science A, Vol. 8, No. 5, pp. 734-74, 2007.

[17] A. Yahyaouy, J. Sabor, H. Gualous, and M. Lamrini, "Modeling And Implementation Of A Multi-Agent Architecture For Intelligent Energy Management In An Electric Vehicle," Journal Of Theoretical And Applied Information Technology, Vol 37, No. 2, 2012.

[18] A. Yahyaouy, J. Sabor, H. Gualous, and M. Lamrini, "Intelligent energy management based on multi-agent approach in a hybrid vehicle," IJCSNS International Journal of Computer Science and Network Security, Vol. 9, No. $11,2009$.

\section{BIOGRAPHIES OF AUTHORS}

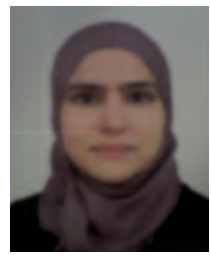

Sihem Nasri was born in Tunis, Tunisia, in 1986.

She received the Master's degree in Electronics from the Faculty of Sciences of Tunis (FST) in 2011. Currently, she is pursuing the Ph.D. degree in Electronics with the Faculty of Sciences of Tunis, in the laboratory of Innovation of communicant and cooperative mobiles (Innov'Com), the Higher School of Communication of Tunis (SUPCOM). Her research interests include electrical power systems integrating energy storage devices and power system management.

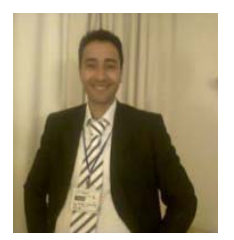

Sami Ben Slama received the engineer, master and doctorate degrees, in electronics from Faculty of sciences of Tunis (FST), respectively in 2005, 2009 and 2014. He is assistant professor in King Abdul-Aziz University, Jeddah Saudi Arabia. He field of interest concerns the photovoltaic power , energy system, and Matlab modeling.

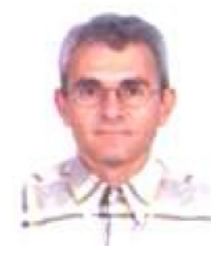

Adnane Cherif received the engineer, master and doctorate degrees from National Engineering School of Tunis (ENIT), in Tunisia. He is a university teacher in Electronics at Faculty of Sciences of Tunis (FST). He is responsible of the master specialty communication systems and networks. His field of interest concerns photovoltaic power system, digital signal processing, energy system designing and modeling. 